\title{
Pengenalan Tanda Tangan Menggunakan Algoritma Single Layer Perceptron
}

\author{
Dimas Agung Riansa, Widodo, Bambang Prasetya Adhi \\ ${ }^{1}$ Mahasiswa Prodi Pendidikan Teknik Informatika dan Komputer, Teknik Elektro, FT - UNJ \\ ${ }^{2,3}$ Dosen Prodi Pendidikan Teknik Informatika dan Komputer, Teknik Elektro, FT - UNJ \\ riansad21@gmail.com, ${ }^{2}$-widodo@unj.ac.id, ${ }^{3}$ bambangpadhi@unj.ac.id
}

\begin{abstract}
Abstrak
Tanda tangan adalah sebuah tulisan tangan yang digunakan untuk mengesahkan sebuah dokumen atau surat Keterdapatan tanda tangan dalam sebuah dokumen mengartikan bahwa pihak yang menandatangani mengetahui dan menyetujui seluruh isi dari dokumen. Hal ini menyebabkan tanda tangan dapat dipalsukan oleh pihak yang tidak bertanggung jawab. Tanda tangan dapat dikenali keaslianya secara manual atau dengan penggunaan komputer dengan menggunakan jaringan syaraf tiruan (JST). Perceptron adalah salah satu algoritma jaringan syaraf tiruan yang dapat digunakan untuk mengenali tanda tangan dengan akurat. Algoritma Perceptron merupakan sebuah algoritma yang digunakan untuk supervised learning (Pembelajaran Terarah) yang dapat mengklasifikasi sebuah input yang bersifat linearly seperable (dapat dipisahkan secara linier) kedalam kelas-kelas tertentu. Peneliti menggunakan tanda tangan dari 5 pejabat fakultas teknik universitas negeri Jakarta, terdapat 15 tanda tangan asli masing masing pejabat dan terdapat juga 15 tanda tangan palsu masing masing pejabat, secara keseluruhan terdapat 150 tanda tangan yang akan dijadikan sebagai data uji (data test) dan data latih (data train). $\mathrm{K}$ fold-cross validation digunakan untuk mendapatkan tingkat akurasi yang valid dari penggunaan algoritma perceptron. Hasil pengenalan tanda tangan menggunakan algoritma perceptron yang tingkat akurasinya diukur dengan menggunakan $k$ fold-cross validation, memiliki rata-rata akurasi algoritma $78.667 \%$

Kata kunci : klasifikasi, tanda tangan, perceptron
\end{abstract}

\section{Pendahuluan}

Tanda tangan yang berasal dari Bahasa latin Signare adalah sebuah tulisan tangan yang digunakan untuk mengesahkan sebuah dokumen atau surat. Tanda tangan dapat berbentuk nama seseorang yang diberikan gaya penulisan tertentu, hal ini menyebabkan tanda tangan sebagai sebuah hal yang unik karena setiap orang memiliki perbedaan. Tanda tangan dapat digunakan sebagai identifikasi dari pemilik tanda tangan. Keterdapatan tanda tangan dalam sebuah dokumen mengartikan bahwa pihak yang menandatangani mengetahui dan menyetujui seluruh isi dari dokumen. Hal ini menyebabkan tanda tangan dapat dipalsukan oleh pihak yang tidak bertanggung jawab.

Tanda tangan dapat dikenali secara manual akan tetapi hal ini membutuhkan keahlian khusus dan tingkat ketelitian yang tinggi. tetapi pada zaman modern ini pengenalan keaslian tanda tangan dapat dengan mudah dilakukan oleh sebuah komputer dengan menggunakan jaringan syaraf tiruan (JST), berbeda dengan pengenalan manual pengenalan dengan komputer tidak memerlukan keahlian khusus ataupun tingkat ketelitian yang tinggi dari pengguna. Pengenalan dengan komputer dapat dengan mudah menentukan keaslian sebuah tanda tangan, tetapi pengenalan dengan komputer sudah sewajarnya masih berada dibawah pengawasan ahli atau hanya sebagai alat bantu. Pengenalan tanda tangan menggunakan komputer membutuhkan algoritma tertentu.

Perceptron adalah salah satu algoritma jaringan syaraf tiruan (JST) yang dapat digunakan untuk mengenali tanda tangan dengan akurat. Algoritma Perceptron merupakan sebuah algoritma yang digunakan untuk supervised learning (Pembelajaran Terarah) yang dapat mengklasifikasi sebuah input yang bersifat linearly seperable (dapat dipisahkan secara linier) kedalam kelas-kelas tertentu. Untuk pengenalan tanda tangan pola akan terlebih melalui fase pembelajaran, pada fase tersebut perceptron mempelajari seluruh pola tanda tangan yang dimasukan, setelah fase pembelajaran terdapat fase pengenalan dimana algoritma perceptron akan mengenali pemilik tanda tangan yang dimasukan.

Hal tersebut yang membuat penulis tertarik untuk memahami algoritma Perceptron dan menggunakannya dalam pembuatan sistem pengenalan tanda tangan. 


\section{Dasar Teori}

\section{Tanda Tangan}

Tanda tangan adalah sebuah tulisan tangan yang diberi gaya tertentu dan dapat digunakan untuk mengesahkan sesuatu dokumen atau perjanjian. Tanda tangan merupakan salah satu bentuk identitas seseorang.

Contoh-contoh tanda tangan setiap orang umumnya identik namun tidak sama. Artinya tanda tangan seseorang sering berubah-ubah setiap waktu. Perubahan ini menyangkut posisi, ukuran maupun faktor tekanan tanda tangan. Pada kenyataannya, perubahan-perubahan tersebut dipengaruhi oleh waktu, umur, kebiasaan dan keadaan mental tertentu (Abbas, 1994).

Menurut N. Siregar (2012) pada skripsinya menyatakan bahwa tanda tangan mempunyai karakteristik sebagai berikut:

1. Tanda tangan adalah bukti otentik

2. Tanda tangan jarang dilupakan.

3. Tanda tangan tidak dapat dipindah untuk digunakan ulang.

4. Tanda tangan tidak dapat disangkal.

5. Dokumen yang telah ditandatangani tidak dapat diubah.

6. Tanda tangan sulit dipalsukan.

\section{Perceptron}

Jaringan lapis tunggal perceptron (Single Layer Perceptron) terdiri dari beberapa unit pemroses (neuron) seperti gambar 2.1, yang terhubung dan mempunyai beberapa input serta satu atau lebih output. Single Layer Perceptron sering juga disebut dengan Perceptron. Perceptron menghitung jumlah nilai perkalian penimbang dan masukan dari parameter permasalahan yang kemudian dibandingkan dengan nilai threshold bila nilai keluaran lebih besar dari threshold maka keluarannya adalah satu, sebaliknya adalah nol.

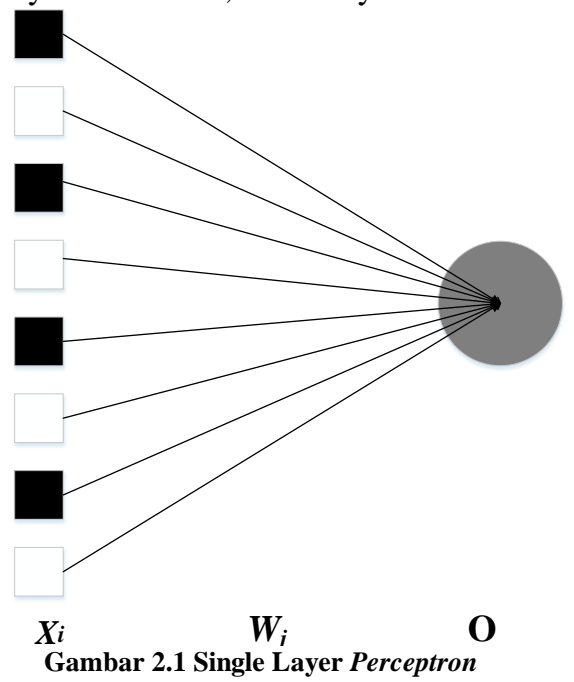

Pernyataan ini merupakan hasil proses pelatihan yang dengan kata lain adalah pernyataan ya dan tidak (satu dan nol). Secara matematis dapat dituliskan sebagai berikut: Jumlah perkalian penimbang dan parameter masukan adalah,

$I=w_{j} x_{i}$

Dimana $x_{i}$, adalah input dan $w_{j}$ adalah penimbang (bobot). Bila $I>T$ maka keluaran $O=1$ sebaliknya $O=0$ dimana $T$ adalah threshold. Nilai awal penimbang adalah bilangan kecil antara nol sampai dengan satu yang dipanggil secara acak.

Perceptron dapat dipresentasikan dan hanya fungsi pemisah linear yang dapat dipisahkan dengan perceptron seperti pada gambar 2.2

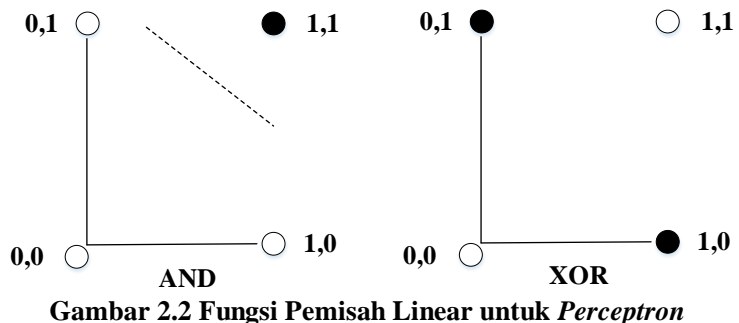

Pelatihan pada perceptron dilakukan dengan merubah nilai penimbangnya sehingga sesuai dengan kebutuhan yang dilakukan dengan membandingkan keluaran dari jaringan dengan targetnya :

$$
w \text { baru }_{j i}=w \text { lama }_{\mathrm{ji}}+a\left(t_{j}-O_{j}\right) x_{i}
$$

$\mathrm{t}_{\mathrm{j}}$ adalah target, dan $a$ adalah bilangan konstan bernilai kecil natara 0,1 sampai 0,9 yang disebut sebagai laju pelatihan (learning rate).

Contoh kasus operasi AND seperti pada gambar 2.2. pertama lakukan pengacakan pada bobot (W) kemudian dilakukan perhitungan perkalian antara input (I) dan bobot (W) seperti gambar 2.3

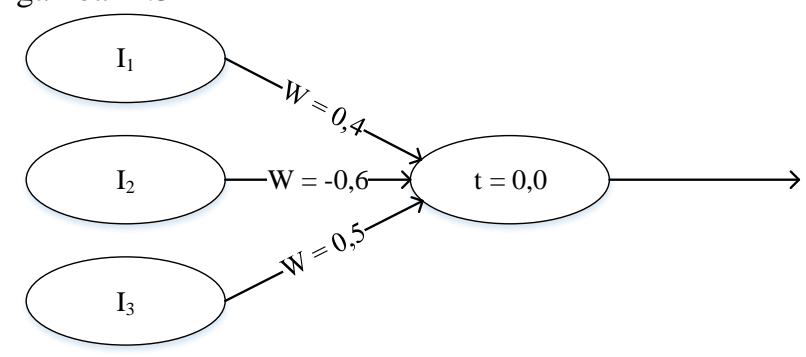

Gambar 2.3 Perhitungan Pelatihan Perceptron

Perhitungan pelatihan perceptron

\begin{tabular}{|c|c|c|c|c|}
\hline $\mathbf{I}_{1}$ & $\mathbf{I}_{\mathbf{2}}$ & $\mathbf{I}_{\mathbf{3}}$ & Penjumlahan & Output \\
\hline 0 & 0 & 1 & $\begin{array}{c}(0 * 0,4)+\left(0_{-}^{*}-0,6\right)+(1 *+0,5) \\
=0,5\end{array}$ & 1 \\
\hline 0 & 1 & 1 & $\begin{array}{c}(0 * 0,4)+(1 *-0,6)+(1 *+0,5) \\
=-0,1\end{array}$ & 0 \\
\hline 1 & 0 & 1 & $\begin{array}{c}(1 * 0,4)+\left(0_{-}^{*}-0,6\right)+(1 *+0,5) \\
=0,9\end{array}$ & 1 \\
\hline 1 & 1 & 1 & $\begin{array}{c}(1 * 0,4)+(1 *-0,6)+(1 *+0,5) \\
=0,3\end{array}$ & 1 \\
\hline
\end{tabular}


Output diperoleh dengan melakukan fungsi aktivasi, dalam kasus AND dilakukan dengan unit step yaitu bila kurang dari nol output $=0$, bila lebih output $=1$. Error diperoleh apabila terjadi perbedaan antara target dengan output jaringan. Jika error tidak sama dengan nol maka bobot (W) diperbaiki dengan cara membandingkan bobot baru dengan bobot lama di tambah learning rate, selisih output dengan target, dan input :

$$
w \text { baru }_{j i}=w_{\text {lama }}+a\left(t_{j}-O_{j}\right) x_{i}
$$

\section{K fold Cross-validation}

Cross validation atau yang terkadang disebut rotation estimation adalah sebuah teknik validasi untuk menilai bagaimana hasil analisis statistik akan menyamakan sebuah kelompok data independen. Cross validation sering digunakan dalam percobaan yang bertujuan untuk memprediksi. Dalam cross validation kelompok data $\mathrm{K}$ akan dipisah secara acak kedalam kelompok yang jumlahnya sama $\left(\mathrm{K}_{1}, \mathrm{~K}_{2}, \ldots ., \mathrm{K}_{\mathrm{n}}\right)$ lalu setiap kelompok data masing masing akan dijadikan data train dan data test jumlah percobaan yang dilakukan sama dengan jumlah kelompok yang ada. Jika hanya terdapat 2 kelompok atau 2 fold cross validation maka apabila $\mathrm{K}_{1}$ dijadikan data test maka $\mathrm{K}_{2}$ merupakan data train untuk percobaan kedua $\mathrm{K}_{1}$ merupakan data train dan $\mathrm{K}_{2}$ merupakan data test. Nilai akurasi dari k fold cross validation merupakan nilai rerata dari hasil yang benar setiap percobaan.

\section{Metodologi}

Penelitian dilakukan di laboratorium komputer Jurusan Teknik Elektro Universitas Negeri Jakarta, dimulai dari bulan April 2016 sampai bulan Oktober 2016.

Perangkat keras dalam penelitian ini menggunakan seperangkat komputer dengan spesifikasi seperti di bawah ini :
1. Prosesor Intel Core i7-4700 CPU @2.40GHz (8CPUs)
2. Memori 8192 RAM
3. NVIDIA GeForce $755 \mathrm{~m}$
4. Mouse
5. Keyboard

Adapun perangkat lunak yang digunakan adalah sebagai berikut :

1. Sistem operasi Windows 8.1 SL 64-bit

2. Microsoft Office 2016

3. Epson Scan

4. Matlab R2014b

Diagram Alir Penelitian dapat dilihat pada gambar berikut

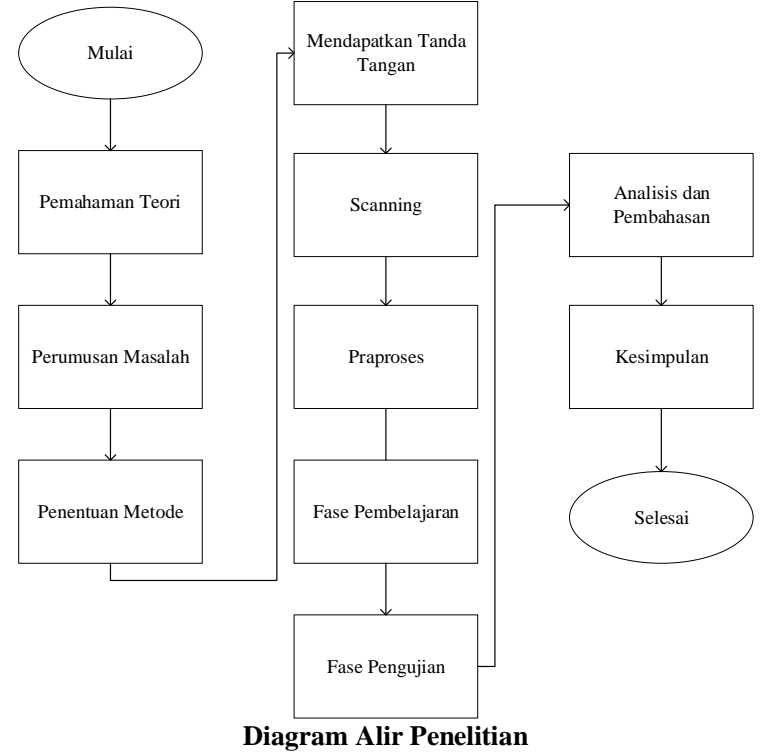

\section{Hasil dan Analisis}

Data tanda tangan yang diperoleh dalam penelitian ini diambil secara langsung dari dari pejabat fakultas teknik UNJ. Jumlah data tanda tangan yang diperoleh adalah 75 tanda tangan asli yang diambil dari 5 pejabat fakultas teknik yaitu:

- Dr. Yuliatri S., M.Pd.

- Drs.Pitoyo Yuliatmojo, MT.

- Prof. Dr. Ivan Hanafi, M.Pd

- Massus Subekti, S.Pd, MT

- Syufrijal, MT.

Dan 75 tanda tangan palsu untuk setiap tanda tangan asli yang diambil dari beberapa mahasiswa fakultas teknik sehingga keseluruhan tanda tangan berjumlahkan 150 tanda tangan.

Setiap tanda tangan diberikan nama file, sebagai contoh tanda tangan Dr. Yuliatri S., M.Pd. akan memiliki nama file sebagai berikut Bu Yuli001 untuk tanda tangan asli dan Bu Yuli Palsu001 untuk tanda tangan palsu maka file akan memiliki angka 001 sampai 015 untuk setiap tanda tangan asli atau palsu yang ada. Tiga angka belakang nama file ini untuk selanjutnya akan disebut sebagai nomor file.

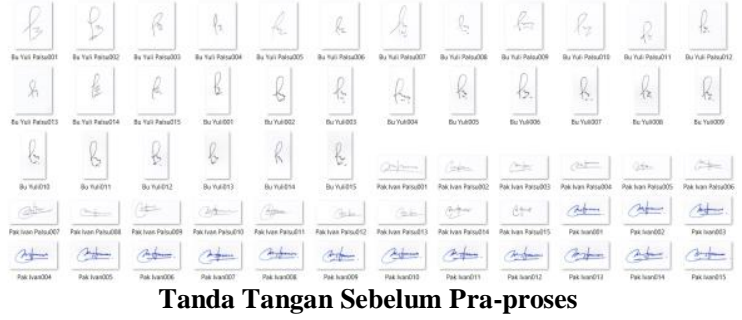

Pra-proses akan terlebih dahulu dilakukan untuk seluruh tanda tangan, pra-proses meliputi beberapa hal grayscale, normalisasi, pemotongan citra, perubahan jenis file, penajaman citra. 


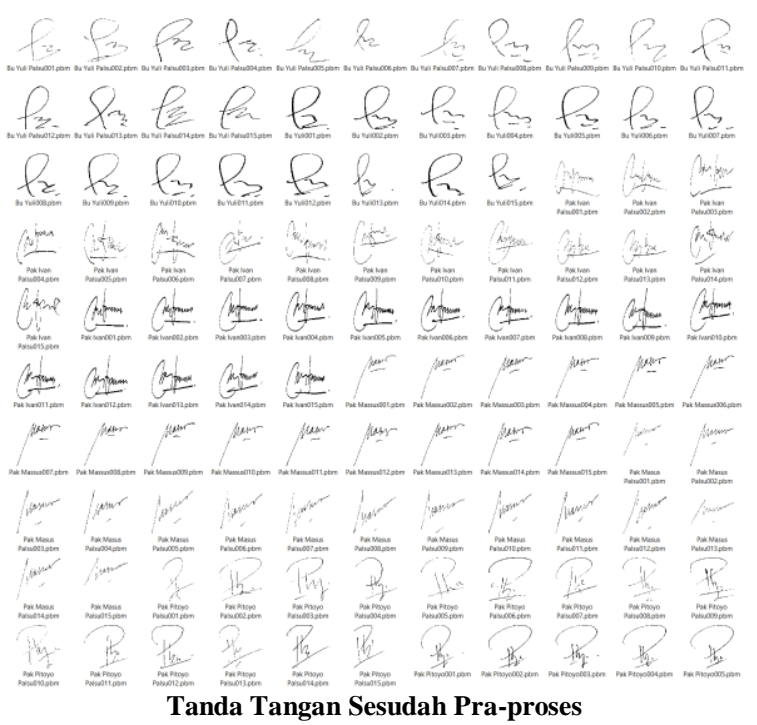

Setelah semua tanda tangan telah di pra-proses maka selanjutnya akan dilakukan proses pelatihan dan pengujian yang menggunakan model 10 foldcross validation untuk mendapatkan hasil yang dapat dipergunakan, teknik analisis data model 10 fold-cross validation berarti proses pelatihan dan pengujian dilakukan sebanyak 10 kali atau terdapat 10 percobaan. setiap percobaan wajib memiliki setidaknya satu dari setiap tanda tangan yang ada (asli dan palsu). Pengambilan tanda tangan dilakukan dengan berdasarkan kepada sorting komputer secara pengurutan berdasarkan nama file.

Percobaan ganjil / genap akan memiliki jumlah tanda tangan masing masing pejabat yang sama hal terjadi karena pengambilan tanda tangan dilakukan berdasarkan kepada sorting nama file secara berurutan.

Berikut adalah salah satu percobaan dari 10 fold-cross validation.

Percobaan 1

Train

Data train percobaan 1

\begin{tabular}{|c|l|c|c|}
\hline No & \multicolumn{1}{|c|}{ Nama File } & Nomor File & Jumlah \\
\hline 1 & Bu Yuli Palsu & $003-015$ & 13 \\
\hline 2 & Bu Yuli & $003-015$ & 13 \\
\hline 3 & Pak Ivan Palsu & $003-015$ & 13 \\
\hline 4 & Pak Ivan & $003-015$ & 13 \\
\hline 5 & Pak Massus & $003-015$ & 13 \\
\hline 6 & Pak Massus Palsu & $002-015$ & 14 \\
\hline 7 & Pak Pitoyo Palsu & $002-015$ & 14 \\
\hline 8 & Pak Pitoyo & $002-015$ & 14 \\
\hline 9 & Pak Syufrijal Palsu & $002-015$ & 14 \\
\hline 10 & Pak Syufrijal & $002-015$ & 14 \\
\hline Test & & \\
\hline
\end{tabular}

Data test percobaan 1

\begin{tabular}{|c|l|c|c|}
\hline No & \multicolumn{1}{|c|}{ Nama File } & Nomor File & Jumlah \\
\hline 1 & Bu Yuli Palsu & $001-002$ & 2 \\
\hline
\end{tabular}

\begin{tabular}{|c|l|c|c|}
\hline 2 & Bu Yuli & $001-002$ & 2 \\
\hline 3 & Pak Ivan Palsu & $001-002$ & 2 \\
\hline 4 & Pak Ivan & $001-002$ & 2 \\
\hline 5 & Pak Massus & $001-002$ & 2 \\
\hline 6 & Pak Massus Palsu & 001 & 1 \\
\hline 7 & Pak Pitoyo Palsu & 001 & 1 \\
\hline 8 & Pak Pitoyo & 001 & 1 \\
\hline 9 & Pak Syufrijal Palsu & 001 & 1 \\
\hline 10 & Pak Syufrijal & 001 & 1 \\
\hline
\end{tabular}

terdapat 135 tanda tangan asli dan palsu yang akan digunakan sebagai data train dan 15 tanda tangan asli dan palsu yang digunakan sebagai data test

Dalam algoritma perceptron, perceptron tidak dapat menerima langsung input matriks biasa

\begin{tabular}{|r|r|r|r|}
\hline 10 & 9 & 8 & \\
\hline 7 & 10 & 8 & \\
\hline 1 & 7 & 4 & \\
\hline & & & \\
\cline { 2 - 4 } & & &
\end{tabular}

Matriks biasa

seluruh matriks harus terlebih dahulu dirubah menjadi bentuk matriks 1-dimensi.

\begin{tabular}{|r|r|}
\hline 10 & \\
\hline 7 & \\
\hline 1 & \\
\hline 9 & \\
\hline 10 & \\
\hline 7 & \\
\hline 8 & \\
\hline 8 & \\
\hline 4 & \\
\hline
\end{tabular}

Matriks 1-dimensi dari gambar sebelumnya

Setelah matriks dijadikan matriks 1-dimensi maka matriks telah dapat digunakan untuk masuk kedalam algoritma perceptron, tetapi sebelum matriks dari data train dimasukan kedalam perceptron, sebuah target harus terlebih dahulu ditetapkan.

Hal ini dikarenakan perceptron merupakan algoritma supervised learning yang berarti perceptron memerlukan data yang telah dikenali terlebih dahulu sebelum mengklasifikasikan data yang belum dikenali dan dikarenakan perceptron juga bersifat linearly seperable maka akan terdapat 5 target yang berbeda untuk 5 perceptron yang berbeda. 
Masing-masing target berfungsi untuk memisahkan satu tanda tangan terhadap tanda tangan lainnya, misal target yang digunakan untuk mengenali tanda tangan bu yuli maka target tersebut hanya akan mengenali tanda tangan bu yuli saja.

Setelah target ditetapkan maka perceptron langsung digunakan dan di train dengan perintah matlab :

net $=$ perceptron;

net $=$ train $($ net $, \mathrm{P}, \mathrm{T})$;

dimana $\mathrm{P}$ adalah matriks data train yang telah dijadikan 1-dimensi dan $\mathrm{T}$ adalah target yang telah ditetapkan sebelumnya berikut adalah proses train algoritma perceptron di matlab.

Setelah seluruh perceptron di train maka perceptron telah siap untuk mengklasifikasi data yang tidak terdapat dalam data train untuk mencoba pengklasifikasian data dari perceptron yang telah di train dapat dengan menggunakan perintah matlab:

Sim (net, S)

Dimana net merupakan perceptron yang telah di train dan $\mathrm{S}$ adalah sebuah data test yang tidak terdapat pada data train, data test juga harus berupa matriks 1-dimensi.

Setelah mendapatkan hasil dari seluruh percobaan 10 fold-cross validation maka untuk mendapatkan tingkat akurasi yang sebenarnya didapatkan dengan mencari rerata dari seluruh hasil yang didapat.

Hasil Tingkat Akurasi 10 fold-cross validatio
\begin{tabular}{|c|c|}
\hline Percobaan 1 & $86.67 \%$ \\
\hline Percobaan 2 & $73.33 \%$ \\
\hline Percobaan 3 & $86.67 \%$ \\
\hline Percobaan 4 & $86.67 \%$ \\
\hline Percobaan 5 & $80 \%$ \\
\hline Percobaan 6 & $80 \%$ \\
\hline Percobaan 7 & $73.33 \%$ \\
\hline Percobaan 8 & $60 \%$ \\
\hline Percobaan 9 & $80 \%$ \\
\hline Percobaan 10 & $80 \%$ \\
\hline Hasil & $78.667 \%(79 \%)$ \\
\hline
\end{tabular}

Dari tabel terlihat bahwa percobaan kedelapan memiliki tingkat akurasi terendah sedangkan tingkat akurasi tertinggi terdapat pada percobaan 1, 3, dan 4 .

Secara keseluruhan terjadi 2 dimana perceptron salah mengenali tanda tangan palsu sebagai tanda tangan asli, terjadi juga 26 data dimana perceptron salah mengenali tanda tangan asli sebagai tanda tangan palsu, dan terjadi 5 data yang salah klasifikasi dimana tanda tangan seseorang dikenali sebagai tanda tangan orang lain.

\section{Kesimpulan dan Saran}

Kesimpulan yang diperoleh setelah melalui tahap-tahap dari pengenalan tanda tangan menggunakan algoritma Perceptron adalah:

1. Pengenalan tanda tangan pejabat Fakultas Teknik Universitas Negeri Jakarta dapat dilakukan dengan menggunakan algoritma Single-layer Perceptron

2. Hasil pengenalan menggunakan algoritma Perceptron diukur tingkat akurasinya dengan menggunakan metode $\mathrm{K}$ fold-cross validation, dengan hasil akurasi algoritma sebesar $78.667 \%$

3. Aplikasi dari penelitian ini adalah untuk membuat sebuah sistem yang dapat mengidentifikasi keaslian sebuah tanda tangan untuk mencegah kemungkinan pemalsuan tanda tangan pada dokumendokumen penting

Beberapa masukan untuk penelitian berikutnya yang berhubungan dengan pengenalan tanda tangan adalah sebagai berikut:

1. Menambah jumlah data train, karena jumlah data train yang digunakan berbanding lurus dengan tingkat akurasi dari algoritma Perceptron.

2. Menggunakan algoritma lain seperti Backpropagation, untuk dapat membandingkan hasilnya agar dapat mengetahui algoritma yang lebih baik untuk digunakan untuk penelitian selanjutnya

3. Jika menggunakan media kertas dan alat tulis pastikan ketebalan tanda tangan agar dapat terbaca dengan baik pada proses scanning.

4. Mengimplementasikan penghilangan noise agar mendapat hasil yang lebih baik.

5. Menggunakan deteksi tepi atau edgedetection agar dapat mendapatkan ciri dari sebuah tanda tangan.

\section{Daftar Pustaka:}

Abbas, R. (1994), A Prototype System for off-line Signature Verification using Multilayered Feedforward Neural Networks. Thesis Departement of Computer Science, RMIT

Godse AP. \& Godse DA. (2007) Digital Computer Fundamentals. First Edition. Technical Publications pune 
Hartarto, dkk. (2011) DATA TRANSFORMATION

PADA DATA MINING. Prosiding Konferensi Nasional "Inovasi dalam Desain dan Teknologi" IDeaTech 2011

Hendradjaya, Bayu. (1995) Catatan Kuliah Pengolahan Citra.

Munir, R. (2002) Diktat kuliah Pengolahan Citra, Edisi Kedua. Departemen Teknik Informatika ITB

Kohavi, Ron (1995). "A study of cross-validation and bootstrap for accuracy estimation and model selection". Proceedings of the Fourteenth International Joint Conference on Artificial Intelligence. San Mateo, CA: Morgan Kaufmann. 2 (12): 1137-1143

Kusumaningtyas, EM. \& Badriyah, T. \& Sigit, R. (2005) Modul Ajar Kecerdasan Buatan. Politeknik Elektronika Negeri Surabaya

Poskanzer, J. (1991). NetPBM User Manual Diakses $30 \quad$ september 2016 (http://netpbm.sourceforge.net/doc/pbm.html).

Putra, D. (2010) Pengolahan Citra Digital. Yogyakarta: Andi

Reddy, M. BMP MS-Windows bitmap format. Diakses $\quad 30 \quad$ september 2016 (http://www.martinreddy.net/gfx/2d/BMP.txt)

Rostamian, R. (2014). Programming Projects in C for Students of Engineering, Science, and Mathematics. the society for industrial and applied mathematics

Siahaan, A. (2011) Pengenalan Karakter Dan Manajemen Database Pada Formulir Isian Menggunakan Jaringan Syaraf Tiruan Dengan Metode Learning Vector Quantization (LVQ)

Siang, JJ. (2009). Aplikasi Jaringan Syaraf Tiruan dan Pemrograman Menggunakan MATLAB. Yogyakarta: Andi.

Siregar, N. (2012) Strategi Otentikasi Pesan Menggunakan Digital Signature Dengan Metode DSA (Digital Standard Algorithm)

Sunarto. (2008) Buku TIK SMA/MA Kelas XII. Grasindo 